\title{
Factors Associated with Relapse in Men with Alcohol Dependence Versus Opioid Dependence: A Comparative Study From Western Nepal
}

\author{
Khan T A ${ }^{1}$, Dutta $A^{2}$, Subedi $S^{3}$
}

\begin{abstract}
Introduction: Drug abuse is a worldwide problem that affects millions of people and Nepal is no exception. Relapse is a major problem in management of substance use disorder. Hence it becomes important to understand the factors contributing to relapse in order to ensure relapse prevention. This study was done with the aim to compare clinico-demographic correlates of relapse in alcohol dependence and opioid dependence and also to know the reasons for relapse in both groups. Method: This is a crosssectional comparative study with the sample collected from three different rehabilitation centers from Nepalgunj. The sample include those male clients with alcohol dependence and opioid dependence who had relapsed at least once in past after some period of abstinence. Total of 80 male subjects i.e. 40 in each group were enrolled in the study. Structured questionnaire was developed by the researcher and was used to collect the data from respondents. The data were statistically analyzed. Result: Some clinic-demographic disparity was observed in both groups. Alcohol group had more subjects from Bahun and Chettri caste, longer total duration of illness whereas opioid group had more Muslims, younger ageand greater number of middle socio-economic clients, more number of substances used in past and higher prevalence of criminal act. The commonest reason for relapse in both groups found to be desire for positive mood. Peer pressure, social or family problems, craving, negative mood state and concentration difficulties were other factors found to be contributing to relapse. Narcotic Anonymous was the most preferred modality of treatment opted by both groups in past in order to quit substance whereas only $22.5 \%$ of subjects consulted to doctor. Conclusion: Social determinants play a critical role in substance use and its relapse and should be addressed alongside physical and psychological determinants for better outcome. Common factors play role for relapse in both groups. Study warrants increased need of mental health awareness programme among substance abusers.
\end{abstract}

Key words: Alcohol, dependence, Nepal, opioid, relapse

\section{INTRODUCTION}

As per ICD-10, a cluster of physiological, behavioral, and cognitive phenomena in which the use of a substance or a class of substances takes on a much higher priority for a given individual than other behaviors that once had greater value is called dependence syndrome ${ }^{1}$.

Drug abuse is a global problem that affects millions of people and Nepal is no exception. Globally, it is estimated that in 2012, some 243 million people corresponding to some 5.2 percent of the world population aged 15-64 had used an illicit drugand men are two to three times more likely than women to have used an illicit substance ${ }^{2}$.

Drugs such as cannabis and alcohol were traditionally used in Nepal for centuries. Use of these drugs as part of the cultural

\footnotetext{
1. Dr. Tanveer Ahmed Khan

2. Dr. Ashish Dutta

3. Dr. Sandip Subedi
}

\section{Address for correspondence:}

Dr. Tanveer Ahmed Khan

Department of Psychiatry,

Nepalgunj Medical College \& Teaching Hospital

Nepalgunj, Banke, Nepal

Email: tanveernep8834@gmail.com norms did not create major social problems during that period. However, the types of drug used have been shifted since the last few decades from cannabis to synthetic opiates and chemical substances ${ }^{3}$. In Nepal, apart from alcohol, the major drugs of abuse are cannabis, codeine-containing cough syrup, nitrazepam tablets, buprenorphine injections and heroin (usually smoked, rarely injected). The commonest sources of drugs are other drug-using friends, cross-border supplies from India or medicine shops ${ }^{4}$.

Relapse i.e. return to previous pattern of substance use, is a major problem in management of substance use disorder.Management of substance use disorder is riddled with multiple relapses. Research studies show that $65-70 \%$ of abstinent alcohol dependence subjects relapse within 1 year, especially within the first 3 months of abstinence ${ }^{5,6}$. Studies have reported alarming rates of relapse with opioid addiction compared to other drugs, with one study reporting a relapse rate of up to $91 \%$ in opioid addicts, indicating that the risk for relapse could be higher for opioid addiction than it is for other drug addiction ${ }^{7}$. Hence it becomes important to understand the factors contributing to relapse in order to ensure relapse prevention. The aim of my study was to compare clinicodemographic correlates of relapse in alcohol dependence and opioid dependence and also to know the reasons for relapse in both groups. 


\section{MATERIAL AND METHODS}

This is a cross-sectional comparative study. Sample for the study was collected from three different rehabilitation centers from Nepalgunj. The sample include those male clients with alcohol dependence and opioid dependence who had relapsed at least once in past after some period of abstinence. Total of 80 male subjects i.e. 40 in each group were enrolled in the study. Structured questionnaire was developed by the researcher and was used to collect the data from respondents during the study period of 2 weeks i.e. from $20^{\text {th }}$ September to $4^{\text {th }}$ October, 2018. Analysis of data was done by SPSS version 20 .

\section{RESULT}

Socio-demographic profile of respondents shows that Bahun and Chettri were major caste in both groups with slight predominance in alcohol dependence group. Muslims were more in opioid dependence group. The findings were statistically significant. The most common age in both groups was 19 to 30 years with younger in opioid group compared to alcohol group but overall pattern appeared statistically insignificant.

Education, occupation and marital status were almost comparable in both groups. Most of the respondents belonged to middle socio-economic status in both group with greater number in opioid group i.e. $95 \%$ where as it was $80 \%$ in alcohol group. Duration of illness was significantly longer with mean $9.988 \pm 6.608$ years in alcohol dependence group in comparison to $5.925 \pm 4.303$ years in opioid dependence group. Total number of substances used in opioid group was significantly more with mean $3.15 \pm 1.578$ than alcohol group. Number of relapses and longest period of abstinence was almost similar in both groups.

\begin{tabular}{|c|c|c|c|}
\hline Caste & $\begin{array}{c}\text { Alcohol Dependence } \\
\qquad \mathrm{N}=\mathbf{4 0}(\%)\end{array}$ & $\begin{array}{l}\text { Opioid Dependence } \\
\qquad \mathrm{N}=40(\%)\end{array}$ & $P$ value \\
\hline Bahun/ Chetri & $25(62.5)$ & $17(42.5)$ & \multirow{4}{*}{$0.042^{*}$} \\
\hline Dalit & $6(15)$ & $4(10)$ & \\
\hline Janajati & $7(17.5)$ & $8(20)$ & \\
\hline Muslim & $2(5)$ & $11(27.5)$ & \\
\hline \multicolumn{4}{|c|}{ Age Group (years) } \\
\hline$<18$ & $5(12.5)$ & $6(15)$ & \multirow{4}{*}{0.055} \\
\hline $19-30$ & $18(45)$ & $28(70)$ & \\
\hline $31-45$ & $13(32.5)$ & $4(12.5)$ & \\
\hline$>45$ & $4(10)$ & $1(2.5)$ & \\
\hline \multicolumn{4}{|c|}{ Education } \\
\hline Illeterate & $3(7.5)$ & $6(15)$ & \multirow{5}{*}{0.461} \\
\hline Primary & $13(32.5)$ & 7 (17.5) & \\
\hline Metriculation & $10(25)$ & $14(35)$ & \\
\hline Upto $12^{\text {th }}$ & $10(25)$ & $10(25)$ & \\
\hline Graduation And above & $4(10)$ & $3(7.5)$ & \\
\hline \multicolumn{4}{|c|}{ Occupation } \\
\hline Unemployed & $11(27.5)$ & $13(32.5)$ & \multirow{4}{*}{0.513} \\
\hline Student & $6(15)$ & $10(25)$ & \\
\hline Business & $16(40)$ & $13(32.5)$ & \\
\hline Service holder & $7(17.5)$ & $4(10)$ & \\
\hline \multicolumn{4}{|c|}{ Marital status } \\
\hline Unmarried & $17(42.5)$ & $21(52.5)$ & \multirow{3}{*}{0.649} \\
\hline Married & $20(50)$ & $17(42.5)$ & \\
\hline Divorced or separated & $3(7.5)$ & $2(5)$ & \\
\hline \multicolumn{4}{|c|}{ Socio-economic status } \\
\hline Low & $8(20)$ & $2(5)$ & \multirow{2}{*}{$0.043^{*}$} \\
\hline Middle & $32(80)$ & $38(95)$ & \\
\hline
\end{tabular}

"Significant $(P<0.05)$

Table I: Socio-demographic profile of both groups 
Khan et al.: Factors Associated with Relapse in Men with Alcohol Dependence Versus Opioid Dependence: A Comparative Study From Western Nepal

\begin{tabular}{|l|c|c|c|}
\hline & $\begin{array}{c}\text { Alcohol Dependence } \\
\mathbf{N}=\mathbf{4 0}(\mathbf{\%})\end{array}$ & $\begin{array}{c}\text { Opioid Dependence } \\
\mathbf{N = 4 0}(\mathbf{\%})\end{array}$ & P value \\
\hline Duration of Illness (years) & $9.988 \pm 6.608$ & $5.925 \pm 4.303$ & $0.002^{*}$ \\
\hline Number of relapses & $3.90 \pm 3.136$ & $3.10 \pm 2.351$ & 0.201 \\
\hline Longest period of abstinence (days) & $275.05 \pm 393.910$ & $264.05 \pm 385.999$ & 0.900 \\
\hline $\begin{array}{l}\text { Total number of substances used } \\
\text { during illness period }\end{array}$ & $2.00 \pm 1.240$ & $3.15 \pm 1.578$ & $0.001^{*}$ \\
\cline { 2 - 4 }
\end{tabular}

*Significant $(\mathrm{P}<0.05)$, SD- Standard Deviation

Table II: Substance use history in both the groups

\begin{tabular}{|c|c|c|c|}
\hline Family history of substance use & $\begin{array}{l}\text { Alcohol Dependence } \\
\qquad \mathrm{N}=\mathbf{4 0}(\%)\end{array}$ & $\begin{array}{l}\text { Opioid Dependence } \\
\qquad \mathrm{N}=40(\%)\end{array}$ & $P$ value \\
\hline Yes & $15(37.5)$ & $10(25)$ & \multirow{2}{*}{0.228} \\
\hline No & $25(62.5)$ & $30(75)$ & \\
\hline \multicolumn{4}{|c|}{ History of criminal record } \\
\hline Yes & $12(30)$ & $24(60)$ & \multirow{2}{*}{$0.007^{*}$} \\
\hline No & $28(70)$ & $16(40)$ & \\
\hline
\end{tabular}

*Significant $(\mathrm{P}<0.05)$

Table III: Additional substance use history in both groups

\begin{tabular}{|l|c|c|c|}
\hline & $\begin{array}{c}\text { Alcohol Dependence } \\
\mathbf{N = 4 0 ( \% )}\end{array}$ & $\begin{array}{c}\text { Opioid Dependence } \\
\mathbf{N = 4 0 ( \% )}\end{array}$ & P value \\
\hline Negative mood state & $9(22.5)$ & $7(17.5)$ & \\
\hline Desire for positive mood & $22(55)$ & $21(52.5)$ & \\
\hline Social or family problems & $14(35)$ & $11(27.5)$ & \\
\hline External or peer pressure to use & $12(30)$ & $19(47.5)$ & \\
\hline Sleep problems & $6(15)$ & $7((17.5)$ & \\
\hline Craving/ Urge & $10(25)$ & $14(35)$ & \\
\hline Concentration difficulties & $10(25)$ & $6(15)$ & \\
\hline Lack of insight & $2(5)$ & $8(20)$ & \\
\hline
\end{tabular}

"Multiple Responses

Table IV: Reasons for relapse

\begin{tabular}{|l|c|c|}
\hline & Alcohol Dependence & Opioid Dependence \\
\hline & $\mathbf{N}=\mathbf{4 0}(\%)$ & $\mathbf{N}=\mathbf{4 0}(\%)$ \\
\hline Doctor & $9(22.5)$ & $9(22.5)$ \\
\hline NA concept & $33(82.5)$ & $27(67.5)$ \\
\hline Herbal medicines & $6(15)$ & $3(7.5)$ \\
\hline
\end{tabular}

*Multiple Responses

Table V: Modality of treatment receivedby the subjects to quit substance in past* 
Most of the subjects cited 2 or 3 reasons for relapse; the most common reason in both groups found to be desire for positive mood. Peer pressure, social or family problems, craving, negative mood state and concentration difficulties were other factors commonly found to be attributed to relapse in both groups. Narcotic Anonymous was the most preferred modality of treatment opted by both groups in past in order to quit substance and only $22.5 \%$ of subjects consulted to doctor.

\section{DISCUSSION}

Socio-demographic profile of this study reveals that upper caste i.e. Bahun and Chettri were most common caste in both groups with slight predominance in alcohol dependence group whereas Muslims were significantly more in opioid dependence group than alcohol dependence group. Similar finding was reported by Pathak DC, who did a study in Surkhet district and found that $55.2 \%$ of drug abuser belonged to Bahun and Chhetri caste ${ }^{8}$. Muslim being more in opioid group than alcohol group could be because of religious prohibition about use of alcohol among them.

Study reveals that about $85 \%$ of respondents in opioid group were below 30 years of age whereas it was only $57.5 \%$ in alcohol group. The earlier age for development of a dependence pattern was nearly significant in the opioid group is consistent with other studies in the literature ${ }^{9,10}$. It could be attributable to the highly addictive properties of opioid. Alcohol dependence is slow to develop. Education, occupation and marital status were almost comparable in both groups. Most of the respondents belonged to middle socio-economic status in both group with greater number in opioid group i.e. $95 \%$ where as it was $80 \%$ in alcohol group. Since these substances are costly to afford for chronic use especially opioid, the problem appeared more prevalent in middle socioeconomic groups than low socio-economic group.

The duration of illness in the alcohol group was significantly longer than the opioid group and the number of substances used during illness period was found to be more in opioid group. Similar finding was observed by Kadam $\mathrm{M}$ et al. ${ }^{9}$ Longer duration of illness at presentation in alcohol use disorder is due to later development of social and occupational dysfunction as compared to opioid. Poly substance use is common in opioid dependence. Aich TK et.al found in his study that $73.4 \%$ of opioid abusers were poly-substance users ${ }^{11}$.

Impulsivity, novelty seeking, past gateway drug use, or temporary switch to a cheaper drug are possible reasons of high prevalence of poly-substance use in opioid group. No significant differences in number of relapses and duration of longest abstinence in both groups were seen in my study. This finding is in accordance with a previous study ${ }^{9}$.

Higher proportion of candidates in opioid group had history of criminal act in past. Similar finding was observed in another study ${ }^{9}$. Drug use causes crime either through the need to fund drug use through economic necessity ${ }^{12}$ or because of psychopharmacological changes precipitated by drug ingestion $^{13,14}$.

The most common reason for relapse in both groups found to be desire for positive mood. Peer pressure, social or family problems, craving, negative mood state and concentration difficulties were other factors commonly found to be contributing to relapse in both groups. Similar results were observed in some previous studies ${ }^{9,15,16}$.

Narcotic Anonymous was the most preferred modality of treatment opted by both groups in past in order to quit substance and only $22.5 \%$ of subjects consulted to doctor. This finding is similar with a previous study done at Dharan where Sapkota S. et.al. reported that $68.1 \%$ of clients of drug addiction were treated by NA concept whereas only $24 \%$ respondents received treatment with medicine ${ }^{15}$. Some of the reasons for not consulting doctor in both groups could be due to inability to afford the cost of care, believing that the problem could be handled without treatment, not knowing where to go for services, lack of awareness and stigma associated with it.

\section{CONCLUSION}

Some disparity in clinico-demographic profile was observed in both groups. Alcohol group had more subjects from Bahun and Chettri caste, longer total duration of illness whereas opioid group had more Muslim subjects, younger age, more number of middle socio-economic clients, more number of substances used during illness period and higher prevalence of criminal act. Such disparities indicate that social determinants play a critical role in substance use and its relapse and should be addressed alongside physical and psychological determinants.

The commonest reason for relapse in both groups found to be desire for positive mood. Peer pressure, social or family problems, craving, negative mood state and concentration difficulties were other factors found to be contributing to relapse. This indicates common reasons for relapse in both groups. Appropriate measures regarding these factors should be taken during management in order to prevent relapse. Narcotic Anonymous was the most preferred modality of treatment opted by both groups in past in order to quit substance and only $22.5 \%$ of subjects consulted to doctor. This warrants increased need of mental health awareness programme among substance abusers.

\section{REFERENCES}

1. The ICD-10 Classification of Mental and Behavioural Disorders: Clinical descriptions and diagnostic guidelines.

2. UNODC, "World drug report" United Nations publication, New York. 2014; 11-25.

3. Survey Report on Current Hard Drug Users in Nepal - 2069. Government of Nepal Central Bureau of Statistics. 
4. Chatterjee A, Uprety L, Chapagain M, Kafle K. Drug abuse in Nepal: A rapid assessment study. Bulletin on narcotics 48(1-2):1133. February 1996.

5. Anton RF, O'Malley SS, Ciraulo DA, Cisler RA, Couper D, Donovan $D M$, et al. Combined pharmacotherapies and behavioral interventions for alcohol dependence: The COMBINE study: A randomized controlled trial. JAMA 2006; 295: 2003-17.

6. Dawson DA, Grant BF, Stinson FS, Chou PS, Huang B, Ruan WJ. Recovery from DSM-IV alcohol dependence: United States, 20012002. Addiction 2005; 100: 281-92.

7. Smyth BP, Barry J, Keenan E, Ducray K. Lapse and relapse following inpatient treatment of opiate dependence. Ir Med J 2010; 103: 176-9.

8. Pathak DC. Demographic Prevalence of Drug Abuse in youth: Cases from the Surkhet District of Nepal. JOURNAL OF ADVANCED ACADEMIC RESEARCH (JAAR) July 2016; Vol. 3. No. II: 82-91.

9. Kadam M, Sinha A, Nimkar S, Matcheswalla Y, De Sousa A. A comparative study of factors associated with relapse in alcohol dependence and opioid dependence. Indian J Psychol Med 2017;39:627-33.

10. Mattoo SK, Basu D, Malhotra A, Malhotra R. Relapse precipitants, life events and dysfunction in alcohol and opioid dependent men. Indian J Psychiatry 2003;45:39-44.

11. Aich TK, Sahal,Ram D, Ranjan S, Subedi S. A Comparative Study On136 Opioid Abusers In India and Nepal. J Psychiatrists" Association of Nepal Vol .2, No.2, 2013.

12. Bennett T., Holloway K., Farrington D. The statistical association between drug misuse and crime: a meta-analysis. Aggress. Violent Behav. 2008;13:107-118.

13. Boyum D., Kleiman M. Substance abuse policy from a crimecontrol perspective. In: Wilson J., Petersilia J., editors. Crime: Public Policies for Crime Control. Institute for Contemporary Studies Press; Oakland CA: 2002.

14. Brownstein H. Drugs and voilent crime. In: Brownstein H., editor. The Handbook of Drugs and Society. John Wiley and Sons, Ltd; West Sussex UK: 2016.

15. Sapkota S., Khadka A., G Akela G. Contributing factors to relapse of drug addiction among clients attending rehabilitation centers of Dharan, Nepal. Journal of Chitwan Medical College 2016; 6(17): 20-25.

16. Sunder S, Kaur S, Kaur J. A study of drug relapse and its associated factors among cases admitted in Swami Vivekananda Drug Deaddiction Centre, GMC, Amritsar. International Journal of Interdisciplinary and Multidisciplinary Studies (IJIMS).2014: 2 (2);100-105. 